\title{
Ergosterol from the soilborne fungus Ganoderma boninense.
}

\begin{abstract}
Ergosterol is the main component of the fungal membrane and is not found in plants or other microbial cells. Therefore, it can be a useful biomarker for the quantification of fungal biomass. We are now reporting the first isolation and characterisation of ergosterol from the mycelium of G. boninense. The ergosterol structure was detected by Thin Liquid Chromatography (TLC) and Ultra Performance Liquid Chromatography (UPLC) and confirmed with Gas Chromatography coupled with Mass Spectrometry (GCMS) and Nuclear Magnetic Resonance (NMR) analysis.
\end{abstract}

Keyword: Ergosterol; Ganoderma boninense. 